\title{
Inhibition of human LDL lipid peroxidation by phenol-rich beverages and their impact on plasma total antioxidant capacity in humans
}

\author{
Mauro Serafini, ${ }^{*}$ João A.N. Laranjinha, ${ }^{\dagger}$ Leonor M. Almeida, ${ }^{\dagger}$ and G. Maiani* \\ *Antioxidant Research Laboratory, National Institute for Food and Nutrition Research, Rome, \\ Italy and ${ }^{\dagger}$ Laboratório de Bioquímica, Faculdade de Farmácia, Universidade de Coimbra, \\ Coimbra, Portugal
}

\begin{abstract}
Mounting evidence shows that phenol-rich beverages exert strong antioxidant activity. However, in vivo evidence has produced conflicting results. In the present study, we studied the impact of the ingestion of $300 \mathrm{~mL}$ of black and green tea, alcohol-free red wine, alcohol-free white wine, or water on plasma total antioxidant capacity in five healthy volunteers. Red wine has the highest content of phenolics $(3.63 \pm 0.48 \mathrm{~g} Q \mathrm{Q} / \mathrm{L})$, followed by green tea $(2.82 \pm 0.07 \mathrm{~g} Q E / L)$, black tea $(1.37 \pm 0.15 \mathrm{~g} Q E / L)$, and white wine $(0.31 \pm 0.01 \mathrm{~g} Q E / L)$. Plasma total antioxidant capacity values of subjects who drank green tea rose at $30 \mathrm{~min}(\mathrm{P}<0.05)$. After black tea and red wine ingestion, the peaks were at 50 min $(\mathrm{P}<0.05$ and $\mathrm{P}<0.01$, respectively). No changes were observed in the control and white wine groups. Red wine and green tea were the most efficient in protecting low density lipoprotein from oxidation driven by peroxyl and ferril radicals, respectively. Phenol-rich beverages are a natural source of antioxidants; however, the phenolic content alone cannot be considered an index of their in vivo antioxidant activity. (J. Nutr. Biochem. 11:585-590, 2000) () Elsevier Science Inc. 2000. All rights reserved.
\end{abstract}

Keywords: antioxidant capacity; LDL; wine; tea; phenolics; plasma; humans

\section{Introduction}

Advances in understanding the role of free radicals in the pathogenesis of degenerative diseases and in the process of aging suggest a potential health-promoting role of dietary antioxidants. Recent evidence suggests that many antioxidant compounds, commonly called "phytochemicals" and not yet identified as nutrients in plant foods, are bioactive. ${ }^{1,2}$ Phytochemicals include numerous substances such as tannins, phytoestrogens, tocotrienols, and phenolic compounds. Phenolic compounds comprise a considerable number of compounds (more than 4,000) present in large amounts in plant foods, ${ }^{3,4}$ tea, and wine. ${ }^{5}$

Epidemiological studies have shown that consumption of phenol-rich beverages (PRB) such as tea and wine correlates with reduced coronary heart disease mortality. ${ }^{6,7}$

Address correspondence to Dr. Mauro Serafini, Antioxidant Research Laboratory, National Institute for Food and Nutrition Research, Via Ardeatina 546, 00178 Rome, Italy.

Received April 5, 2000; accepted August 15, 2000.
Nevertheless, it has been claimed that wine might, indeed, be one of the most active ingredients involved in the protective effect of the Mediterranean Diet and one of the possible explanations of the "French Paradox." 8,9 The putative role that PRB are thought to play in the prevention of oxidative stress-linked diseases is mainly based on their antioxidant properties. ${ }^{10}$ In vitro studies have consistently showed that wine and tea phenolics have significant antioxidant activity as measured by their ability to inhibit low density lipoprotein (LDL) oxidation ${ }^{11-13}$ and in neutralizing free radicals. ${ }^{10,14}$ However, experimental ex vivo and in vivo studies have produced contrasting results, ${ }^{15-22}$ suggesting that the in vivo situation cannot be extrapolated on the basis of the in vitro evidence (i.e., the bioavailability of phenolics is limited and depends upon such different variables as nutrient interactions, gut microflora, etc.).

In the present study, the in vitro and in vivo antioxidant properties of black tea (BT), green tea (GT), alcohol-free red wine (RW), and alcohol-free white wine (WW) have been studied in two different models: (1) evaluation of the in vitro total antioxidant capacity and effect on LDL 
oxidized by a physiologically relevant oxidant (ferrylmioglobin) and by a controlled flux of peroxyl radicals, and (2) the impact on plasma total radical-trapping antioxidant parameter (TRAP) in humans.

\section{Methods and materials}

All chemicals were purchased from Sigma Chemical Co. (St. Louis, MO USA) unless otherwise stated. 6-Hydroxy-2,5,7,8tetramethyl-chroman-2-carboxylic acid (Trolox) was purchased from Aldrich Chemical Co. (Milwaukee, MI USA), 2,2'-diazobis(2-amidinopropane) dihydrochloride (ABAP) was purchased from Wako Pure Chemical Industries Ltd. (Osaka, Japan), hydrogen peroxide was purchased from Merck (Darmstadt, Germany) as a $30 \%$ solution, and cis-Parinaric acid (PnA) was purchased from Molecular Probes (Eugene, OR USA). Solutions and reagents for TRAP assays were made using Milli-Q (Millipore, Bedford, MA USA) double-distilled water (resistance $>18 \mathrm{~mW} / \mathrm{cm}^{2}$ ), and filtered through Chelex 100 resin $\mathrm{Na}^{+}$form. Tea infusions were prepared using two commercially available brands of tea (Twinings Earl Grey and Birko Chinese green tea, KI). One hundred milliliters of boiling tap water was poured over $2.0 \mathrm{~g}$ of tea leaves, the mixture allowed to steep for $1.5 \mathrm{~min}$, after which it was filtered. RW ("Chianti Classico Rocca Castagnoli" Farm, Siena, Italy), and WW ("Valdadige" bottled by Terre Fredde, Trento, Italy) were used in this study. To separate the nonalcoholic fraction rich in phenolics from the ethanol contained in the wine (a source of possible experimental confounds), the two wines were dealcoholized in a rotary evaporator at $25^{\circ} \mathrm{C}$ for $4 \mathrm{hr}$.

\section{Total phenolic content}

Total phenolic content of the tea and wine was measured according to a modification of the Folin-Ciocalteau colorimetric method. ${ }^{1,23}$ Five hundred microliters of the sample were added to $1 \mathrm{~mL}$ of 1.0 $\mathrm{N}$ HCL, and vigorously vortexed for $60 \mathrm{sec}$. After incubation at $37^{\circ} \mathrm{C}$ for $60 \mathrm{~min}, 1.0 \mathrm{~mL}$ of $2.0 \mathrm{~mol} / \mathrm{L} \mathrm{NaOH}$ in $75 \%$ methanol was added, and the resulting mixture vortexed for $3 \mathrm{~min}$. Then, $1.0 \mathrm{~mL}$ of $10 \%(\mathrm{v} / \mathrm{v})$ phosphoric acid was added to this mixture, and the sample was centrifuged at $1,500 \times g$ for $10 \mathrm{~min}$. The supernatant was removed and kept on ice in the dark, whereas the pellet was extracted again by adding $1.0 \mathrm{~mL}$ of a solution $1: 1(\mathrm{v} / \mathrm{v})$ acetone: water and centrifuged for $10 \mathrm{~min}$ at $2,700 \times g$. The two supernatants were combined and filtered through a HV $0.45 \mu \mathrm{m}$ filter (Millipore SJHV004NS). Two hundred microliters of sample were assayed for total polyphenols with the Folin-Ciocalteau reagent and expressed as Quercetin Equivalents (g QE/L).

\section{TRAP assay}

The method employed to assess the in vitro and in vivo peroxylradical scavenging activities of PRB was developed in our laboratory. ${ }^{24}$ It is based on the protection afforded by plasma or other substrate against the decay of a fluorescent target, R-Phycoerytrhin (R-PE) during a peroxidation reaction. In the present study, samples were added to the reaction mixture made up to a $2.0-\mathrm{mL}$ final volume and preincubated at $37^{\circ} \mathrm{C}$ for $5 \mathrm{~min}$ in $10-\mathrm{mm}$ quartz fluorometer cuvettes. The oxidation reaction was started by adding ABAP at a final concentration of $5.0 \mathrm{mmol} / \mathrm{L}$. The decay of R-PE fluorescence was monitored every $5 \mathrm{~min}$ for $90 \mathrm{~min}$ on a Perkin-Elmer (Norwalk, CT USA) LS-5 Luminescence Spectrometer equipped with a thermostatically controlled cell-holder. The monochromators operated at an excitation wavelength of $495 \mathrm{~nm} / 5$ $\mathrm{nm}$ slit width and an emission wavelength of $575 \mathrm{~nm} / 5 \mathrm{~nm}$ slit width. The results were standardized using Trolox, a water-soluble analogue of $\alpha$-tocopherol.

\section{LDL Isolation and oxidation}

LDL particles were isolated from fresh human plasma by density gradient ultracentrifugation in a Beckman L80 ultracentrifuge (Beckman Instruments, Inc., Palo Alto, CA USA) equipped with a Beckman $70.1 \mathrm{Ti}$ fixed-angle rotor at $65,000 \mathrm{rpm}$ at $15^{\circ} \mathrm{C}$, following the procedure of Vieira et al. ${ }^{25}$. The LDL fraction was then concentrated and simultaneously dialyzed for $45 \mathrm{~min}$ by ultrafiltration under nitrogen to obtain a fraction concentrated in LDL and free of water-soluble antioxidants.

PnA incorporated into LDL particles has been previously used as a probe to study LDL oxidation and its inhibition by antioxidants because it sensitively detects oxidant reactions within the LDL particles and allows for a quantitative characterization of the activity of the antioxidant under study. ${ }^{26}$ The experimental conditions for PnA oxidation were set up as previously described ${ }^{27}$ to ensure that the fluorescence intensity of incorporated PnA was linear with its concentration, and that LDL concentration was high enough to incorporate most of the probe, thus preventing PnA from interfering in the water phase. Changes in fluorescence were monitored with a Perkin-Elmer LS 50B luminescence spectrometer. The standard reaction mixture consisted in $2 \mathrm{~mL}$ phospate buffer (110 mM NaCl, $20 \mathrm{mM}$ phospate, $\mathrm{pH}$ 7.4) containing 3 nmol PnA, $50 \mu \mathrm{M}$ DTPA, and $120 \mu \mathrm{g}$ LDL protein at $37^{\circ} \mathrm{C}$ with gentle stirring. Metmyoglobin was dialyzed against phospate buffer (110 mM NaCl, $20 \mathrm{mM}$ phospate, $\mathrm{pH} 7.4)$ containing 50 $\mu \mathrm{M}$ EDTA and previously passed through Chelex 100 resin $\mathrm{Na}^{+}$ form. The oxidation reaction was initiated by addition of metmyoglobin $(1 \mu \mathrm{M})$, followed 2 min later by hydrogen peroxide $(1.5$ $\mu \mathrm{M})$ or AAPH $(10 \mathrm{mM})$. Beverages were added $1 \mathrm{~min}$ before the peroxide or AAPH. The fluorescence of the probe was recorded in time using excitation and emission wavelengths of 324 and 413 $\mathrm{nm}$, respectively (slit widths $3.5 \mathrm{~nm}$ ). To minimize PnA fluorescence quenching due to the presence of hemoprotein, excitation and emission wavelengths were 310 and $425 \mathrm{~nm}$, respectively. The effect of myoglobin redox transitions on PnA signal was checked.

\section{In vivo study}

Five healthy nonsmoking volunteers, ages 25-50 years, were selected after ascertaining that they had not been taking any vitamin supplements. On the first experimental day after an overnight fast, each subject was asked to ingest a bolus quantity $(300 \mathrm{~mL})$ of water. The same experiment was then repeated on different days using BT, GT, RW, and WW instead of water. The venous blood samples were obtained by antecubital venipuncture, with NaEDTA vacutainers, at times $0,30,50$, and 120 min after the ingestion of the different beverages. Blood samples were immediately centrifuged at $12,000 \times g$ for $3 \mathrm{~min}$, plasma was separated and placed at $-80^{\circ} \mathrm{C}$, and assayed for TRAP within $3 \mathrm{hr}$. The study protocol was approved by the Human Ethics Committee of the National Institute of Nutrition, and written informed consent was obtained from each volunteer.

\section{Statistics}

Statistical analyses were performed using Statview II (Abacus Concepts Inc., Berkeley, CA USA) software for Macintosh. A $P$-value lower than 0.05 was considered statistically significant. Data are expressed as mean \pm SEM or SD.

\section{Results}

\section{In vitro study}

Phenolic content and TRAP values of the beverages are shown in Table 1. RW had the highest amount of phenolics 
Table 1 Total phenolic concentration and total radical-trapping antioxidant parameter (TRAP) of black tea, green tea, alcohol-free red wine, and white wine*

\begin{tabular}{lrrr}
\hline & $\begin{array}{c}\text { Phenolics } \\
\text { (g QE/L) }\end{array}$ & \multicolumn{1}{c}{$\begin{array}{c}\text { TRAP } \\
(\mathrm{mmol} / \mathrm{L})\end{array}$} & \multicolumn{1}{c}{$\begin{array}{r}\text { Regression } \\
(r)\end{array}$} \\
\hline Black tea & $1.37 \pm 0.15$ & $3.5 \pm 0.20$ & 0.994 \\
Green tea & $2.82 \pm 0.07$ & $17.8 \pm 0.08$ & 1.000 \\
Alcohol-free red wine & $3.63 \pm 0.48$ & $40.0 \pm 0.10$ & 0.999 \\
Alcohol-free white wine & $0.31 \pm 0.01$ & $1.9 \pm 0.10$ & 0.998 \\
\hline
\end{tabular}

*Values are mean \pm SD of three separate experiments.

TTRAP value is referred to $8 \mu \mathrm{L}$ of beverage, and represents the number of moles $(\mathrm{mmol} / \mathrm{L})$ of peroxyl radicals trapped per liter of beverage.

${ }^{\ddagger}$ Regression coefficient $(r)$ of linear regression of lag-phase vs. 2, 4, and $8 \mu \mathrm{L}$ of undiluted black tea, diluted 1:200 ( $\mathrm{v} / \mathrm{v})$ alcohol-free red wine, and diluted 1:2 (v/v) green tea, and alcohol-free white wine.

QE-Quercetin Equivalents.

(3.63 $\pm 0.48 \mathrm{~g} \mathrm{QE} / \mathrm{L})$, followed by GT $(2.82 \pm 0.07 \mathrm{~g}$ $\mathrm{QE} / \mathrm{L})$ and $\mathrm{BT}(1.37 \pm 0.15 \mathrm{~g} \mathrm{QE} / \mathrm{L})$, whereas WW presented the lowest phenolic content $(0.31 \pm 0.01 \mathrm{~g} \mathrm{QE} / \mathrm{L})$. The procedure adopted for the dealcoholization did not change the phenol content of the wines (data not shown). RW displayed the highest antioxidant capacity: twice that of GT and at least 10 and 20 times higher than BT and WW, respectively. There were no changes in wine TRAP values after removal of ethanol (data not shown). The correlation coefficient of the regression between increasing amounts of beverages $(2,4$, and $8 \mu \mathrm{L})$ and the length of lag-phase was 0.999 for RW, 0.998 for WW, 1 for GT, and 0.994 for BT.

The effect of phenol-rich beverages on LDL oxidation was determined in our study by PnA assay using different catalysts. These catalysts included AAPH, which generates peroxyl radical at a fixed constant rate in the aqueous phase inducing the chain oxidation of human LDL by a free radical-mediated chain mechanism, ${ }^{28}$ and ferrylmyoglobin, the product of metmyoglobin reaction with $\mathrm{H}_{2} \mathrm{O}_{2} \cdot{ }^{29}$ Ferrylmyoglobin is a strong oxidant able to initiate lipid peroxidation in several lipid systems, but its harmful effect can be counteracted by antioxidants reducing ferrylmyoglobin to the ferric form (for review, see Giulivi and Cadenas) ${ }^{30}$. Figure 1 shows a typical time course of PnA assay. When LDL was challenged with AAPH-derived peroxyl radicals in the absence of external added antioxidants, PnA quickly underwent oxidative modification, as indicated by its rapid fluorescence decay. The presence of increasing amounts of wine $(0.3,0.5$, and $0.7 \mu \mathrm{L})$ in the medium protected PnA and LDL from oxidation in a dose dependent manner. The effect of the different beverages on peroxyl radical-LDL oxidation is displayed in Figure 2. The results are expressed as percent of PnA oxidized with respect to a control without antioxidant after $20 \mathrm{~min}$. RW is the most efficient in protecting LDL from oxidation, followed by GT and BT. At doses similar to the other beverages, WW failed to show any protective effects. Figure 3 shows the effect of the different beverages on the oxidation of PnA-loaded LDL oxidized with metmyoglobin $/ \mathrm{H}_{2} \mathrm{O}_{2}$. GT displayed the stronger protective effect, whereas RW and BT exhibited an intermediate grade of protection and WW was ineffective. When results were standardized for phenolics concentration

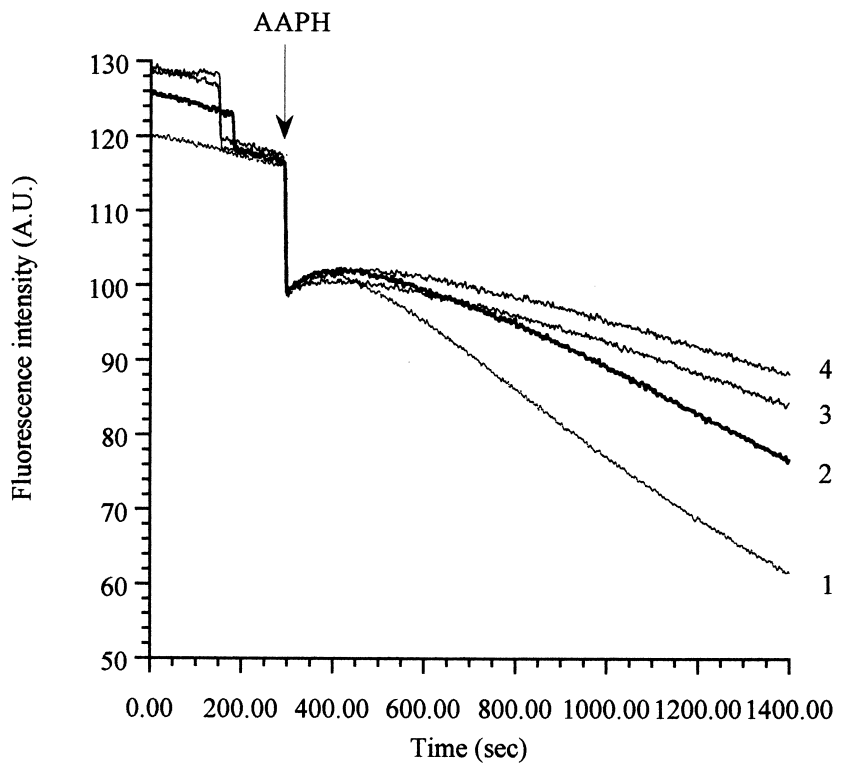

Figure 1 Effect of red wine on $\mathrm{AAPH}$-induced oxidation of parinaric acid $(P n A)$ incorporated in LDL. PnA oxidation rates in LDL particles in the absence (Line 1) and presence of 0.3 (Line 2), 0.5 (Line 3), and 0.7 (Line 4) $\mu \mathrm{L}$ of red wine under conditions described in the Methods and Materials section.

(Table 2), the inhibitory effect of PRB on AAPH-LDL oxidation was related to the phenolic content $(\mathrm{RW}>\mathrm{GT}>$ BT $>$ WW). However, when LDL were oxidized with ferril radicals, the association between phenolic content and antioxidant activity was not observed for GT (Table 2).

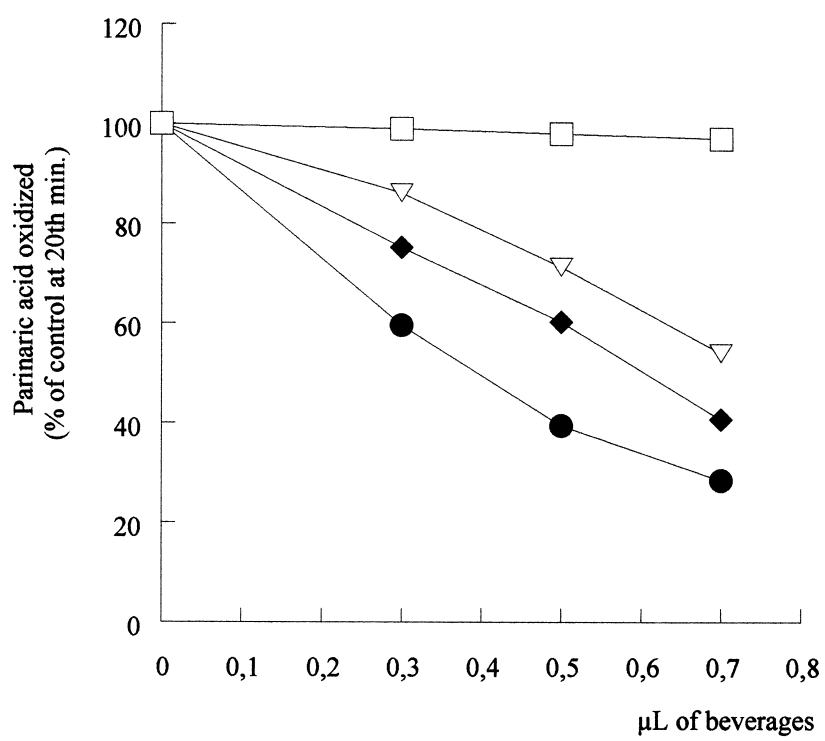

Figure 2 Inhibition of $\mathrm{AAPH}$-induced oxidation of parinaric acid $(\mathrm{PnA})$ incorporated in LDL by black tea $(\Delta)$, green tea $(\bullet)$, red wine $(\bullet)$, and white wine ( $\square$ ). The amount of oxidized PnA was taken 20 min after starting the reaction with AAPH and expressed as \% of control in the absence of beverages. The experimental conditions are described in the Methods and Materials section. 


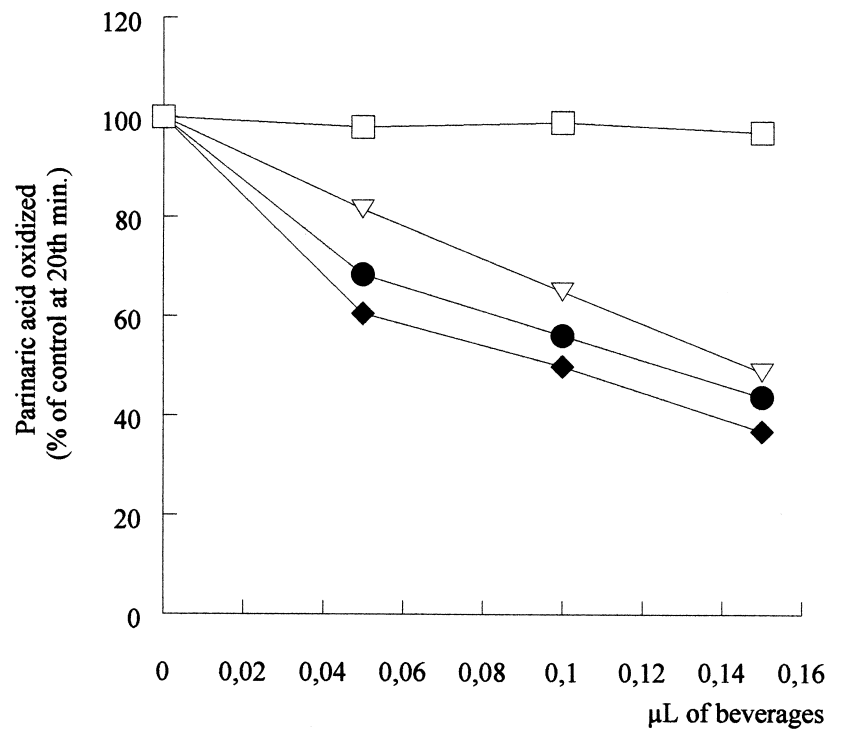

Figure 3 Inhibition of metmyoglobin/ $\mathrm{H}_{2} \mathrm{O}_{2}$-induced oxidation of parinaric acid $(\mathrm{PnA})$ incorporated in LDL by black tea $(\Delta)$, green tea $(\bullet)$, red wine $(\bullet)$, and white wine $(\square)$. The amount of oxidized PnA was taken 20 min after starting the reaction with AAPH and expressed as \% of control in the absence of beverages. The experimental conditions are described in the Methods and Materials section.

\section{In vivo study}

The overall antioxidant effect of acute beverage drinking was assessed by measuring plasma TRAP of the individual response throughout the entire period of observation. Table 3 describes the time trend of plasma TRAP levels after the ingestion of the different beverages: TRAP levels started to increase after $30 \mathrm{~min}$ and reached the peak at $50 \mathrm{~min}(P<$ 0.05 ) for BT. Base-line TRAP values immediately rose for subjects who drank GT $(P<0.05$ at $30 \mathrm{~min})$ and decreased after $50 \mathrm{~min}$. RW raised the antioxidant capacity after 30 $\min (P<0.05)$, peaked at $50 \mathrm{~min}(P<0.01)$, and fell back to baseline values after $2 \mathrm{hr}$, whereas in the WW and control

Table 2 Inhibition of AAPH and metmyoglobin/ $/ \mathrm{H}_{2} \mathrm{O}_{2}$-induced oxidation of parinaric acid $(\mathrm{PnA})$ incorporated in LDL by the same amounts of alcohol-free red wine (RW), green tea (GT), black tea (BT), and white wine (WW) standardized for phenolic concentration*

\begin{tabular}{lccccc}
\hline & \multicolumn{2}{c}{ AAPH } & & \multicolumn{2}{c}{ Metmyoglobin $/ \mathrm{H}_{2} \mathrm{O}_{2}$} \\
\cline { 2 - 3 } \cline { 5 - 6 } & QE $(\mu \mathrm{M})$ & $\begin{array}{c}\text { PnA oxidized } \\
(\%)\end{array}$ & & QE $(\mu \mathrm{M})$ & $\begin{array}{c}\text { PnA oxidized } \\
(\%)\end{array}$ \\
& & & & \\
\hline RW & $3.0 \pm 0.24$ & $39.5 \pm 0.3$ & & $0.6 \pm 0.02$ & $56.1 \pm 0.6$ \\
GT & $2.5 \pm 0.03$ & $60.4 \pm 0.3$ & & $0.4 \pm 0.02$ & $49.9 \pm 0.7$ \\
BT & $1.1 \pm 0.07$ & $71.3 \pm 0.2$ & & $0.2 \pm 0.01$ & $65.0 \pm 0.5$ \\
WW & $0.2 \pm 0.01$ & $98.0 \pm 0.2$ & & $0.05 \pm 0.01$ & $99.0 \pm 0.5$
\end{tabular}

*Values are mean $\pm \mathrm{SD}, n=3$. The same amount of RW, GT, BT, and WW has been used for the experiment with AAPH $(0.5 \mu \mathrm{L})$ and metmyoglobin $/ \mathrm{H}_{2} \mathrm{O}_{2}(0.1 \mu \mathrm{L})$. The amount of oxidized PnA was taken 20 min after starting the reaction with $\mathrm{H}_{2} \mathrm{O}_{2}$ and expressed as \% of control in the absence of beverages.

QE-Quercetin Equivalents. AAPH-2,2'-azobis(2,amidinopropane) hydrochloride. groups, there were no changes in plasma TRAP values over the entire period of observation.

\section{Discussion}

Tea and wine, widely consumed beverages throughout the world, are extremely rich in phenolic compounds. Tea leaves contain more than $35 \%$ of their dry weight in phenolics, the nature of which depending upon the manufacturing procedure. ${ }^{31}$ GT differs from BT in phenolic composition: The former is rich in low molecular weight flavanols (a class of phenolics), the latter is rich in phenoliccondensation products such as theaflavins and thearubigens. Wine also contains flavanols but their chemical profile is different from that of teas: ${ }^{32} \mathrm{RW}$ is rich in antocyanins and in soluble and hydrolizable tannins that represent the condensed form of phenolics, whereas WW does not contain antocyanins. Ample evidence ${ }^{33,34}$ has shown that in vitro antioxidant activity of wine and tea is directly correlated with their phenolic content; however, data from in vivo and ex vivo studies have produced contrasting results. ${ }^{15-22}$

In this study, we compared the antioxidant activity of different PRB in vitro with those in vivo through the measure of the total antioxidant capacity of human plasma after acute ingestion of PRB. The in vitro experiments showed that all of the PRB studied, except for WW, have a remarkably high antioxidant capacity and can inhibit LDL oxidation challenged with ferrylmyoglobin or AAPH with different efficiency. The ranking of the in vitro antioxidant efficiency mirrors the phenolic concentration of the beverages: RW with the higher concentration in phenolics displays the strongest antioxidant capacity, WW with the lower phenolic content has also the lower TRAP value. Phenolic concentration also provides a justification for RW higher efficiency in preventing peroxyl-radical-induced LDL oxidation when compared to tea. However, RW is not so effective when LDL oxidation is driven by ferrylmyoglobin. Under these conditions, GT showed the best protection. These apparent contradictory results may be explained on the basis of differences in scavenging mechanisms necessary to neutralize AAPH-derived peroxyl radicals, or to reduce the strong oxidant ferrylmyoglobin to the harmless metmyoglobin. Both mechanisms avoid LDL oxidation, and phenols are implicated in both. Polymerized phenols in BT and RW may exhibit free hydroxyl groups for peroxyl radical scavenging, but more simple flavanols exhibiting a catechol structure and present in higher concentrations in GT may be better reductants of ferrylmyoglobin. The lack of any effect on LDL oxidation for the WW with both catalysts at the amount where the other beverages are effective may also be explained by its low phenolic content. WW begins to have a protective effect at doses 10 times higher (data not shown), suggesting that the phenolic content of the beverages play a crucial role in preserving LDL from oxidation.

The second part of our study was aimed at studying the effects of acute ingestion of BT, GT, RW, and WW by healthy volunteers on the total antioxidant capacity of plasma. Our results showed that both teas and RW contribute to raise plasma TRAP, but with different modalities. The different time of action for the three beverages mirrors their 
Antioxidant activity of phenol-rich beverages: Serafini et al.

Table 3 Plasma total antioxidant capacity* before and after drinking water, black tea, green tea, and alcohol-free red and white wine

\begin{tabular}{|c|c|c|c|c|c|}
\hline \multirow[b]{2}{*}{$\begin{array}{l}\text { Time } \\
\text { (min) }\end{array}$} & \multicolumn{5}{|c|}{ TRAP } \\
\hline & Water & Black tea & Green tea & $\begin{array}{l}\text { Alcohol-free } \\
\text { red wine }\end{array}$ & $\begin{array}{l}\text { Alcohol-free } \\
\text { white wine }\end{array}$ \\
\hline $\begin{array}{l}\text { T0 } \\
\text { T30 } \\
\text { T50 } \\
\text { T120 }\end{array}$ & $\begin{array}{l}1318 \pm 79 \\
1308 \pm 68 \\
1343 \pm 89 \\
1310 \pm 93\end{array}$ & $\begin{array}{l}1158 \pm 150 \\
1317 \pm 129 \\
1761 \pm 100^{b} \\
1189 \pm 131\end{array}$ & $\begin{array}{l}1303 \pm 160 \\
1826 \pm 185^{a} \\
1570 \pm 161^{b} \\
1488 \pm 125\end{array}$ & $\begin{array}{l}1151 \pm 38 \\
1241 \pm 48^{a} \\
1395 \pm 49^{b} \\
1098 \pm 60\end{array}$ & $\begin{array}{l}1386 \pm 166 \\
1311 \pm 94 \\
1267 \pm 100 \\
1350 \pm 68\end{array}$ \\
\hline
\end{tabular}

*Total radical-trapping antioxidant parameter (TRAP) values are expressed as micromoles of peroxyl radicals trapped per liter of plasma. Values are mean \pm SEM, $n=5$.

a,bValues with different superscripts are significantly different from TO value (Fisher PLSD's test): ${ }^{a} P<0.05,{ }^{b} P<0.01$.

phenolic composition: GT, richer in simple monomers units give the fastest response $(30 \mathrm{~min})$, whereas $\mathrm{BT}$ and $\mathrm{RW}$, rich in polymeric units exerted their effect 20 min later. On the other hand, WW, with the lowest phenolics content, failed to show any protective effect in vivo. Again, the most likely explanation for the lack of effect of the WW is that phenolic concentrations in WW are too low to achieve an increase of phenolic plasma levels able to significantly raise antioxidant potential. These results are in agreement with previous evidence showing that WW drinking did not change phenolic levels ${ }^{1}$ but increased peroxide plasma levels: when WW was added with $1 \mathrm{~g} /$ day of polyphenol powder, phenolic levels significantly increased with a parallel decrease in plasma peroxidation. ${ }^{16}$ However, on the basis of the phenolic content, RW would be expected to show the highest antioxidant in vivo activity, but the percent of increase with respect to base-line of TRAP levels was lower $(21 \%)$ compared to the increase displayed by BT $(52 \%)$ and GT $(40 \%)$.

Alternatively, an important role might be played by the interaction between phenolics and other nutrients contained in the beverages; for instance, the interaction between protein and tannins (high molecular weight phenolics) can lead to the formation of insoluble complexes ${ }^{35}$ that may affect phenolic bioavailability. Although the choice of using alcohol-free wine did not affect the phenolic content and the in vitro antioxidant capacity of the beverage, it may have had consequences on the order of magnitude of the in vivo results. Reduction of the alcohol content of wine has been shown to produce a linear increase in protein-tannin interaction and a parallel decrease in the antioxidant capacity of wine. ${ }^{36}$ Moreover, Duthie et al. ${ }^{37}$ have shown that more phenolics were absorbed from whisky than from wine, ascribing these results to the greater alcohol content of whisky. Along these lines, RW impact on plasma TRAP in our experimental conditions could have been higher if we had used non-dealcoholized wine.

On the other hand, BT displays (on the basis of its in vitro antioxidant activity) an unexpected high in vivo response, confirming previous evidence. ${ }^{19}$ BT contains phenolic condensation products such as theaflavins and thearubigens with molecular weights of about $500-3000,{ }^{31}$ which display a lower in vitro antioxidant activity compared to the free phenolics of GT. ${ }^{38}$ Moreover, Plumb et al..$^{39}$ have shown that polymerization decreases the ability of phenolics to prevent free radical damage in a lipid system. We speculate that modifications in the molecular structure of BT polyphenols may have taken place after ingestion, restoring the antioxidant capacity lost as a consequence of the manufacturing process. We think that the condensed polyphenols might be broken down in the stomach by the acid gastric secretion. The monomer phenolics released by gastric hydrolysis would thus become available for absorption and for exerting their antioxidant activity.

The mixture of different phenolics with different red-ox potentials present in tea and wine represent a vast array of antioxidant compounds that might interact in a synergistic way, carrying out a transient protective in vivo effect through mechanisms still unexplored. In light of this experimental evidence, PRB consumption seems to represent a good natural source of compounds involved in the healthpromoting effects of a diet rich in fruit and vegetables. However, our results also indicate that phenolic content itself cannot be considered a universal index of in vivo antioxidant activity. In fact, the different doses, combinations of different phenolics, interactions with nutrients, food matrix, and chemical nature of either the phenol or the oxidant must be taken into account when evaluating the in vivo antioxidant capacity of PRB.

In addition, our results give indirect evidence of the metabolic processes that may occur during phenolics absorption, the interactions with nutrients leading to different degrees of absorption, and of compounds with distinct physiological activity that need to be identified.

\section{Acknowledgments}

This research was partially supported by the Italian National Research Council short-term fellowship program.

\section{References}

1 Serafini, M., Maiani, G., and Ferro-Luzzi A. (1998). Alcohol-free red wine enhances plasma antioxidant capacity in humans. J. Nutr. 128, 1003-1007

2 Lairon, M. and Amiot, M.J. (1999). Flavonoids in food and natural antioxidants in wine. Curr. Opin. Lipidol. 10, 23-28

3 Velioglu, Y.S., Mazza, G., Gao, L., and Oomah, B.D. (1998). Antioxidant activity and total phenolics in selected fruits, vegetables, and grain products. J. Agric. Food Chem. 46, 4113-4117

4 Vinson, J.A., Hao, Y., Su, X., and Zubik, L. (1998). Phenol antioxidant quantity and quality in foods: Vegetables. J. Agric. Food Chem. 46, 3630-3634 
5 Balentine, D.A., Wiseman, S.A., and Bouwens, L.C.M. (1997). The chemistry of tea flavonoids. Crit. Rev. Food Sci. Nutr. 37, 693-704

6 Friedman, L.A. and Kimball, A.W. (1986). Coronary heart disease mortality and alcohol consumption in Framingham. Am. J. Epidemiol. 24, 481-489

7 Knekt, P., Jarvinen, R., Reunanen, A., and Maatela, J. (1996). Flavonoid intake and coronary mortality in Finland: A cohort study. Br. Med. J. 312, 478-481

8 Renaud, S. and De Lorgeril, M. (1992). Wine, alcohol, platelets and French paradox for coronary heart disease. Lancet 339, 1523-1526

9 Frankel, E.N., Kanner, J., German, J.B., Parks, E., and Kinsella, J.E. (1993). Inhibition of oxidation of human low-density lipoprotein by phenolic substances in red wine. Lancet 341, 454-457

10 Kanner, J., Frankel, E., Granit, R., German, B., and Kinsella, J.E. (1994). Natural antioxidants in grapes and wines. J. Agric. Food Chem. 42, 64-69

11 Frankel, E.N., Waterhouse, A.L., and Teissedre, P.L. (1995). Principal phenolic phytochemicals in selected California wines and their antioxidant activity in inhibiting oxidation of human low-density lipoproteins. J. Agric. Food Chem. 43, 1165-1169

12 Yen, G. and Chen, H. (1995). Antioxidant activity of various tea extracts in relation to their antimutagenicity. J. Agric. Food Chem. 43, 27-32

13 Zhenhua, D., Yuan, C., Mei, Z., and Yunzhong, F. (1991). Inhibitory effect of China green tea polyphenol on the oxidative modification of low-density lipoprotein by macrophages. Med. Sci. Res. 19, 767-768

14 Terao, J., Piskula, M., and Yao, Q. (1994). Protective effect of epicatechin, epicatechin gallate and quercetin on lipid peroxidation in phospholipid bilayers. Arch. Biochem. Biophys. 308, 278-284

15 Cherubini, A., Beal, M.F., and Frei, B. (1999). Black tea increases the resistance of human plasma to lipid peroxidation in vitro, but not ex vivo. Free Rad. Biol. Med. 27, 381-387

16 Nigdikar, S.V., Williams, N.R., Griffin, B.A., and Howard, A.N. (1998). Consumption of red wine polyphenols reduces the susceptibility of low-density lipoproteins to oxidation in vivo. Am. J. Clin. Nutr. 68, 258-265

17 Whitehead, T.P., Robinson, D., Allaway, S., Syms, J., and Hale, A. (1995). Effect of red wine ingestion on the antioxidant capacity of serum. Clin. Chem. 41, 32-35

18 Furhman, B., Lavy, A., and Aviram, M. (1995). Consumption of red wine with meals reduces the susceptibility of human plasma and low-density lipoprotein to lipid peroxidation. Am. J. Clin. Nutr. 61, 549-554

19 Serafini, M., Ghiselli, A., and Ferro-Luzzi, A. (1996). In vivo antioxidant effect of green and black tea in man. Eur. J. Clin. Nutr. 50, $28-32$

20 McAnlis, G.T., McEneny, J., Pearce, J., and Young, I.S. (1998). Black tea consumption does not protect low density lipoprotein from oxidative modification. Eur. J. Clin. Nutr. 52, 202-206

21 Maxwell, S. and Thorpe, G. (1996). Tea flavonoids have little short term impact on serum antioxidant activity. Br. Med. J. 313, 229

22 de Rijke, Y.B., Demacker, N.M.P., Assen, N.A., Sloots, L.M., Katan, M.B., and Stalenhof, A.F.H. (1996). Red wine consumption does not affect oxidizability of low-density lipoproteins in volunteers. Am. J. Clin. Nutr. 63, 329-334

23 Swain, T. and Hillis, E. (1959). The phenolic constituents of Prunus Domestica. The quantitative analysis of phenolic constituents. J. Sci. Food Agric. 10, 63-68
24 Ghiselli, A., Serafini, M., Maiani, G., Azzini, E., and Ferro-Luzzi, A. (1995). A fluorescence based method for measuring total plasma antioxidant capability. Free Rad. Biol. Med. 18, 29-36

25 Vieira, O., Laranjinha, J., Madeira, V., and Almeida, L. (1996). Rapid isolation of low density lipoproteins in a concentrated fraction free from water-soluble plasma antioxidants. J. Lipid Res. 37, 2715-2721

26 Laranjinha, J., Almeida, V., and Madeira, V. (1994). Reactivity of dietary phenolic acids with peroxyl radicals: Antioxiodant activity upon low-density lipoprotein oxidation. Biochem. Pharmacol. 48, 487-494

27 Laranjinha, J.A.N., Almeida, L.M., and Madeira, V.M.C. (1992). Lipid peroxidation and its inhibition in low-density lipoproteins: Quenching of cis-parinaric acid fluorescence. Arch. Biochem. Biophys. 297, 147-155

28 Sato, K., Niki, E., and Shimasaki, H. (1990). Free radical-mediated chain oxidation of low density lipoprotein and its synergistic inhibition by vitamin E and vitamin C. Arch. Biochem. Biophys. 279, 402-405

29 George, P. and Irvine, D.H. (1952). The reaction between metmyoglobin and hydrogen peroxide. Biochem. J. 52, 511-517

30 Giulivi, C. and Cadenas, E. (1994). Ferrylmyoglobin: Formation and chemical reactivity toward electron-donating compounds. Methods Enzymol. 233, 189-202

31 Balentine, A.D. (1992). Manufacturing and chemistry of tea. In Phenolic Compounds in Food and Their Effect on Health I $(\mathrm{H}$. Chi-Tang, Y.L. Chang, and H. Mou-Tuan, eds.), pp. 103-117, ACS, Washington, DC, USA

32 Macheix, J.J., Fleurient, A., and Billot, J. (1990). Fruit Phenolics. CRC Press, Boca Raton, FL, USA

33 Vinson, J.A. and Hontz, B.A. (1995). Phenol antioxidant index: Comparative antioxidant effectiveness of red and white wines. $J$. Agric. Food Chem. 43, 401-403

34 Yu-Li, L., I-Ming, J., Ying-Ling, C., Yu-Chih, L., and Jen-Kun, L. (1996). Composition of polyphenols in fresh tea leaves and associations of their oxygen-radical-absorbing capacity with antiproliferative actions in fibroblast cells. J. Agric. Food Chem. 44, 1387-1394

35 Mehansho, H., Butler, L.G., and Carlson, D.M. (1987). Dietary tannins and salivary proline-rich proteins: Interactions, induction and defense mechanisms. Annu. Rev. Nutr. 7, 423-440

36 Serafini, M., Maiani, G., and Ferro-Luzzi, A. (1997). Effect of ethanol on red wine tannin-protein (BSA) interactions. J. Agric. Food Chem. 45, 3148-3151

37 Duthie, G.G., Pedersen, M.W., Gardner, P.T., Morrice, P.C., Jenkinson, A.M., McPhail, D.B., and Steele, G.M. (1998). The effect of whisky and wine consumption on total phenol content and antioxidant capacity of plasma from healthy volunteers. Eur. J. Clin. Nutr. 52, 733-736

38 Gow-Chin, Y. and Hui-Yin, C. (1995). Antioxidant activity of various tea extracts in relation to their antimutagenicity. J. Agric. Food Chem. 43, 27-32

39 Plumb, G.W., Pascual-Teresa, S., Santos-Buelga, C., Cheynier, V., and Williamson, G. (1998). Antioxidant properties of catechins and proanthocyanidins: Effect of polymerisation, galloylation and glycosylation. Free Rad. Res. 29, 351-358 